\title{
Article \\ Development and Validation of a Masking System for Mitigation of Low-Frequency Audible Noise from Electrical Substations
}

\author{
Rogerio Regazzi ${ }^{1}$, Brunno Cunha ${ }^{1}$, Hugo Villela de Miranda ${ }^{2}$, Juan José Gómez Acosta ${ }^{3}$, Carlos Roberto Hall Barbosa ${ }^{3, *}$ (D), \\ Mauricio Nogueira Frota ${ }^{3}$, João Vitor Souza ${ }^{4}$ and Carlos Augusto Machado Gomes ${ }^{4}$ \\ $1 \quad$ 3R Brasil Tecnologia Ambiental, Av. Rio Branco N 156 sala. 2323, Rio de Janeiro 81270-200, Brazil; \\ isegbusiness@gmail.com (R.R.); brunnocunha@3rbrasil.com.br (B.C.) \\ 2 TRACEL Indústria Eletrônica Ltd., Rua Capitão Guynemer Quadra 18 Lote 1B-Polo Industrial \\ CODIN—Xerém, Duque de Caxias 25250-615, Brazil; hugo.miranda@tracel.com.br \\ 3 Postgraduate Metrology Programme, Pontifical Catholic University of Rio de Janeiro, Marquês de São Vicente \\ Street, 225, Gávea, Rio de Janeiro 22541-041, Brazil; juan_jg@hotmail.com (J.J.G.A.); mfrota@puc-rio.br (M.N.F.) \\ 4 Light Serviços de Eletricidade S/A, Av. Marechal Floriano, 168-B4-2 andar, CEP, Rio de Janeiro 20080-002, Brazil; \\ joao.souza@light.com.br (J.V.S.); carlos.gomes@light.com.br (C.A.M.G.) \\ * Correspondence: hall@puc-rio.br
}

check for updates

Citation: Regazzi, R.; Cunha, B.; de Miranda, H.V.; Acosta, J.J.G.; Barbosa, C.R.H.; Frota, M.N.; Souza, J.V.; Gomes, C.A.M. Development and Validation of a Masking System for Mitigation of Low-Frequency Audible Noise from Electrical Substations. Appl. Sci. 2021, 11,7771. https://doi.org/10.3390/ app11177771

Academic Editor: Woon-Seng Gan

Received: 15 July 2021

Accepted: 13 August 2021

Published: 24 August 2021

Publisher's Note: MDPI stays neutral with regard to jurisdictional claims in published maps and institutional affiliations.

Copyright: (c) 2021 by the authors. Licensee MDPI, Basel, Switzerland. This article is an open access article distributed under the terms and conditions of the Creative Commons Attribution (CC BY) license (https:/ / creativecommons.org/licenses/by/ $4.0 /)$.
Featured Application: Integrated sound system tuned to mask audible noises generated by the operation of electrical substations, aiming to comply with legal requirements.

Abstract: Low-frequency audible noise generated by the magnetostriction effect inherent to the operation of power transformers has become a major drawback, especially in cases where the electrical substation is located in urban areas subject to strict environmental regulations that impose noise limits, differing for day and night periods. Such regulations apply a $+5 \mathrm{~dB}$ penalty if a tonal component of noise is present, which is clearly the case of magnetostriction noise, typically concentrated at twice the industrial frequency $(50 \mathrm{~Hz}$ or $60 \mathrm{~Hz}$, depending on the country). The strategy used to eliminate the tonal characteristics, therefore contributing to establish compliance with the applicable regulation and to alleviate the discomfort it causes to the human ear, consisted in superimposing to the substation noise a masking sound synthesized from "sounds of nature" with suitable intensities, to flatten the noise spectrum while enhancing the soundscape. The masking system (heavy-duty speakers powered by a microprocessor platform) was validated at an already judicialized urban scenario. Measurement results confirmed that the masking solution was capable of flattening the tonal frequencies, whose beneficial effect yielded the cancellation of the public civil action filed by the neighbors. The proposed solution is ready to be replicated in other scenarios.

Keywords: power substation; transformer noise; low-frequency noise; noise masking; soundscape

\section{Introduction}

It is well known that the continuous exposure of the human ear to acoustic noise not only disturbs and seriously compromises the hearing capacity [1,2] but can also endanger the health of those who are exposed to it. For this reason, the noise in urban areas is regulated by strict environmental legislation. This work evaluates the noise level in the vicinity of electric power substations installed in urban areas with high population density. Exposed to constant complaints and legal actions filed by the inhabitants of the surroundings of the substation, the attenuation of the noise generated by the operation of high voltage electrical transformers has deserved the attention of the electricity utility companies. Aware that mitigation of the noise level is not a trivial task, the operation of electrical substations poses technical challenges which require innovative solutions, not usually available through conventional technologies. Despite the significant technological advances related to the design and installation of transformers and subsystems used in electrical substations, the 
attenuation of acoustic noise generated by the operation of high-voltage transformers, even today, is a challenge for managers, researchers, and manufacturers. Particularly, the noise results from a condition intrinsic to the functioning of the transformer itself, caused by the phenomenon of magnetostriction, with tonal characteristics, therefore not feasible to be completely eliminated so as not to cause discomfort to the human ear.

Thus, although it is theoretically possible to attenuate noise by means of acoustic conditioning with attenuating and absorbing technologies, aiming at conforming to the strict normative limits imposed by the environmental regulation, in practice, the success of these solutions is not trivial. Acoustic noise attenuation requires creativity, theoretical and practical experience, and mapping of the sound field, which, in turn, requires access to high-risk environments, use of specialized measurement systems, and georeferenced modeling tools.

The risky environment of an electrical substation (whose safety standards impose minimum distances to the high-voltage transformer in operation) limits the possible measurement points inside the substation and near the transformers, making it difficult to map acoustic power levels and to perform a directivity analysis of the noise source [3]. As a result of these difficulties, carrying out a theoretical analysis of the energy transfer process during the operation of the electrical transformers would allow modeling the system and characterizing the sources [4]. Moreover, a frequency analysis allows identifying the fundamental tonal components of the acoustic signal and their harmonics [5].

This paper is based on the results of an ongoing research and development project (R\&D Light-Aneel 00382-0128/2019), financed with resources from a research-regulated fund managed by the regulatory body of the Brazilian electrical system (Aneel), aiming at reducing the sound pressure level of a broad-band noise that arises from the operation of electrical substations installed in urban areas. The paper describes an acoustic noise masking system designed to eliminate the tonal characteristic of the spectrum, therefore eliminating the discomfort to the human ear and adjusting the sound pressure level to the limits imposed by the environmental legislation. The active masking system was made possible by superimposing to the global noise (which emanates from the substation's operation) "sounds of nature", synthesized in the laboratory, thus masking the perception of the tonal frequencies (around $120 \mathrm{~Hz}$ and first harmonics) by the human ear.

In this context, the research study represents the response of the electricity utility that has been involved in complaints by residents of the substation neighborhood, who claimed to be disturbed by the annoying noise generated by the operation of the substation. The proposed acoustic noise masking system also contributes to minimizing social-environmental impacts, juridical, operational, and interdiction costs associated with the functioning of the substations, problems that proved feasible to be solved by the use of specialized techniques, such as the proposed masking system.

\section{Theoretical Background}

\subsection{Basics of Acoustics}

Acoustic quantities are commonly expressed in decibels (dB), a logarithmic ratio defined by the magnitude of the acoustic power in relation to a reference power level (normally $P_{0}=20 \mu \mathrm{Pa}$ ). However, due to the different sensitivity of the ear to the different frequencies, the raw values obtained are not directly related to the loudness of the sound in question. In order to make the measurements more representative of the loudness associated with any sound, it is often desirable to weigh the values for each frequency in accordance with the way in which the human ear would respond to the sound.

The use of weighting in acoustic measurement is equivalent to making use of filters, allowing frequencies to be given different weights during the measurement process. The reason for assigning different weights to different frequencies is due to the hearing ability of the human ear, which perceives midrange frequencies better than high and low frequencies. In this context, the A-weighting curve allows simulating the response curve of the human ear during measurements. To meet different purposes, the majority of the sound pressure 
measurements (or noise levels) are expressed based on the A-weighting curve, considering that there is, usually, an acceptable correlation between the measured results and the subjective evaluations. In this sense, curve A fulfills the purpose of producing a singlevalue representation of a complete sound spectrum. The A-weighted sound pressure level is then defined as

$$
L_{A}=10 \log _{10}\left(\frac{P_{A}}{P_{0}}\right) d B
$$

The A-weighted equivalent continuous noise level is used as a descriptor of both occupational and environmental noise and, for an average over a period of time $T_{e}$, it may be written in terms of the instantaneous A-weighted sound pressure level as

$$
L_{A_{e q, T e}}=10 \log _{10}\left[\frac{1}{T_{e}} \int_{0}^{T e} 10^{\left.\frac{L_{A}(t)}{10} d t\right]}\right.
$$

In this work, the period $T_{\mathrm{e}}=5 \mathrm{~min}$ was used, leading to the simplified notation $L_{A_{e q}}$ for this descriptor.

Two other descriptors, $L_{10}$ and $L_{95}$, provide statistical insight into sound pressure levels that fluctuate significantly over time. Considering the $L_{A}$ values, $L_{95}$ is the level that has been exceeded $95 \%$ of the time and is often used as an approximation of the background noise level or as a descriptor for continuous noise sources. On the other hand, $L_{10}$ is the level that has been exceeded $10 \%$ of the time and can be used to assess noise from vehicle traffic and other mobile sources.

In practical situations, a specific sound might be of interest, and another specific descriptor $L_{A e q, s p}$ would be defined depending on the situation. In the case of a continuous noise polluted by intrusive noises, $L_{95}$ is generally a good descriptor to assess the sound pressure level generated by the functioning of high-voltage transformers, except in cases where the background noise is so high that it masks the specific noise of interest or makes it impossible to be identified.

\subsection{Environmental Regulation}

The international standards ISO 1996-1:2016 and ISO 1996-2:2017 [6,7], used as the basis for the Brazilian standard NBR 10.151:2019 [8], define the nomenclature and procedures for the measurement of environmental noise in community environments and noise assessment in inhabited areas, aiming at the comfort of the community. The sound pressure levels are limited by each city zone, typically based on the applicable standards, considering the A-weighting, and divided by day time and night time periods.

Furthermore, the aforementioned Brazilian standard defines that, in the case that specific frequencies are identified in the measured noise-characterizing the so-called tonal noise - the measured sound pressure levels shall be penalized in $K_{T}=+5 \mathrm{~dB}$. Noise is considered to be tonal if there is a difference larger or equal to $15 \mathrm{~dB}$ between the specific frequencies and its side frequencies, for frequencies between $25 \mathrm{~Hz}$ and $125 \mathrm{~Hz} ; 8 \mathrm{~dB}$, for frequencies between $160 \mathrm{~Hz}$ and $400 \mathrm{~Hz}$; or $5 \mathrm{~dB}$, for frequencies between $500 \mathrm{~Hz}$ and $10 \mathrm{kHz}$, as depicted in Table 1.

\begin{tabular}{|c|c|}
\hline $\begin{array}{c}\text { Frequency Band }(\mathrm{Hz}) 1 / 3 \text { Octave of } \\
\text { the Frequency of Interest }\end{array}$ & $\begin{array}{c}\Delta P(\mathrm{~dB}), \text { Difference between Sound Pressure } \\
\text { Measured at Both, Central and Adjacent Frequencies }\end{array}$ \\
\hline $25 \mathrm{~Hz}$ to $125 \mathrm{~Hz}$ & $\geq 15 \mathrm{~dB}$ \\
\hline $160 \mathrm{~Hz}$ to $400 \mathrm{~Hz}$ & $\geq 8 \mathrm{~dB}$ \\
\hline $500 \mathrm{~Hz}$ to $10,000 \mathrm{~Hz}$ & $\geq 5 \mathrm{~dB}$ \\
\hline
\end{tabular}

Table 1. Characterization of a tonal sound according to the ABNT NBR 10151:2019 standard.

This is the criterion that characterizes and quantifies the limits for framing the noise component as containing tonal components. As an example, it should be noted that, in the frequency range from $25 \mathrm{~Hz}$ to $125 \mathrm{~Hz}$, the penalty imposed by legislation (i.e., adding 
$+5 \mathrm{~dB}$ to the measured sound power value) only occurs if the difference between the sound pressure measured at the central frequency and at both adjacent frequencies is higher than or equal to $15 \mathrm{~dB}$.

\subsection{Magnetostriction Noise}

Magnetostriction is a physical phenomenon characterized by the dimensional alteration of ferromagnetic materials when excited by magnetic fields [9]. It occurs in magnetic circuits of electrical machines in general and, in particular, in power transformers. More specifically, in the case of power transformers used in high-voltage electrical substations, the acoustic noise is generated by the periodic expansion and contraction of the steel plates that form the laminated core of the transformer, due to the magnetic field that is induced by the flow of alternating electric current through its coils.

This phenomenon of expansion and contraction occurs with double the frequency of the alternating current. For the operating conditions of the Brazilian electrical network, acoustic noise is generated with a characteristic frequency of $120 \mathrm{~Hz}$, in addition to some harmonics (typically, $240 \mathrm{~Hz}$ and $360 \mathrm{~Hz}$ ), and frequencies in the audible range (there may be a variation of these frequencies around nominal values, typically $\pm 0.2 \mathrm{~Hz}$ ). Although the magnetostriction noise from transformers can be attenuated by means of a specific project for restructuring the transformer, this phenomenon is intrinsic to its operation and cannot be completely eliminated.

Thus, the noise of interest is continuous, so $L_{A e q, s p}=L_{95}$ in the cases that the background noise is not high enough to mask the specific noise from the substation. In scenarios with a background noise too high, no assessment can be made. A corrected noise level, $L_{R}$, is then defined based on $L_{A e q, s p}$, taking into account the possible penalty due to the presence of tonal noise, so that that $L_{R}=L_{\text {Aeq,esp }}+K_{T}$ if there is tonal noise, and $L_{R}=L_{\text {Aeq,sp }}$ in the absence of tonal noise.

\section{Materials and Methods}

This section describes the methodology used to study the acoustic noise generated by the operation of an electrical substation installed in an essentially residential area, and also the design and implementation of the masking system. Particularly, it discusses experimental procedures to identify the primary sources of noise and measurement of the relevant acoustic parameters required to support the development of a masking system, which superimposes "sounds of nature" to the primary noise generated by the transformers of the substation aiming at eliminating the undesirable tonal characteristics of the noise. Measurements were performed in compliance with recommendations of the ABNT NBR 10151:2019 standard [8], based on ISO 1996-2 standards [6,7], which establishes procedures for measuring and evaluating sound pressure levels outside buildings.

The electrical substation selected to support the study is located in a neighborhood in the south zone of the city of Rio de Janeiro, a highly populated residential area nearby to Copacabana Beach. In compliance with the recommendations of the International Olympic Committee (IOC), the capacity of the substation was expanded to 80 MVA, using two transformers of 40 MVA each, here referred to as Trafo\#1 and Trafo\#2.

\subsection{Characterization of the Substation's Internal and External Environments}

Figure 1 illustrates a photo taken by an instrumented drone (DJI Mavic Air), showing an image of the substation (highlighted in yellow) and its residential surroundings. The discomfort caused by the noise from the substation culminated in complaints and legal action imposed by residents of one of the buildings (identified in green) surrounding the substation, also shown in the same figure. 


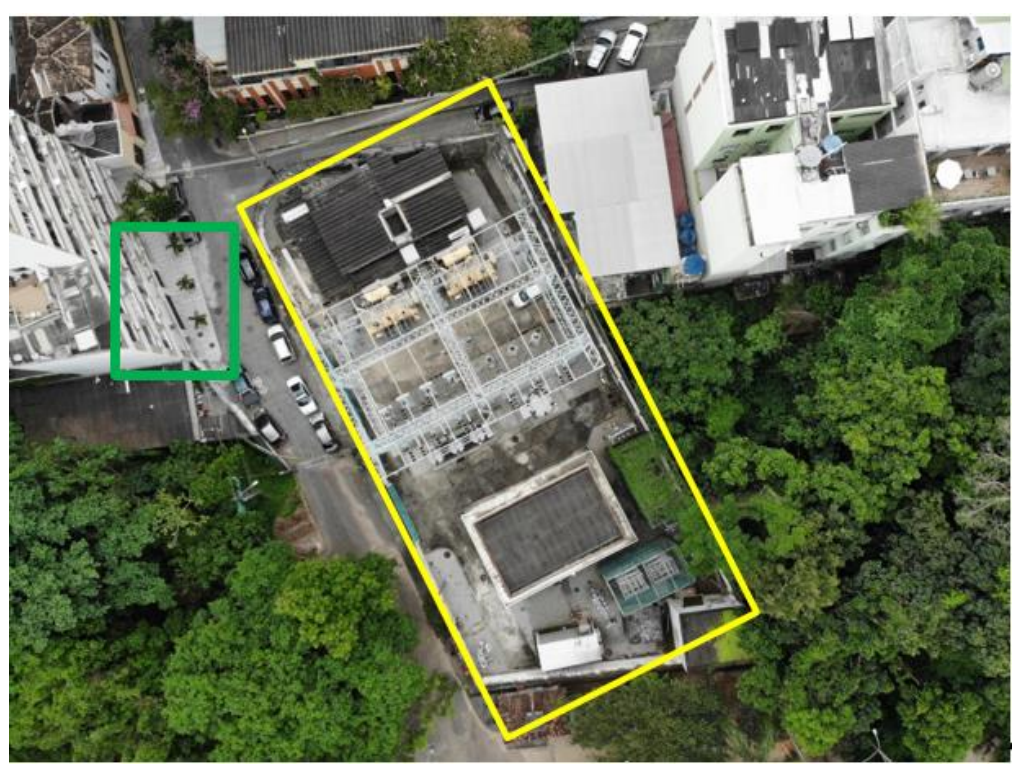

Figure 1. Location of the substation (in yellow) and the source of the complaint (in green).

Figure 2 shows a closer view of the two transformers installed in the substation plant.

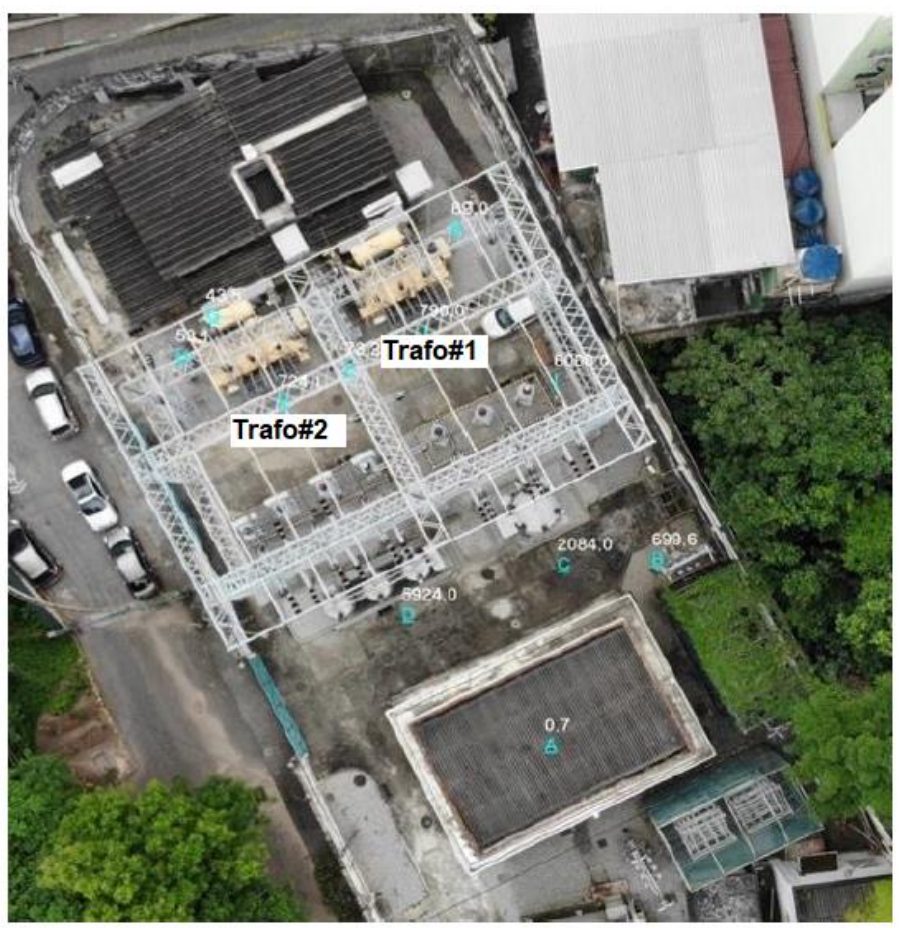

Figure 2. Closer view of the substation, showing the two high-voltage transformers.

\subsection{Characterization of the Primary Sound Sources}

The primary sources of acoustic noise attributed to the operation of the substation are the high-voltage transformers (Trafo \#1 and Trafo \#2). To these, other secondary sources of residual noise are superimposed, such as "nature noises" (e.g., bird songs, insect buzzing), noises generated by human activity (e.g., traffic of vehicle, people, and animals' passers-by voices), and not negligible noises generated by air conditioning equipment, water pumps, and ventilation systems installed in the neighborhood buildings themselves.

To monitor the acoustic field perceived by residents of the neighborhood surrounding the substation, eight measurement points were selected outside the substation yard, 
indicated in Figure 3. The measurement point labeled "Cont. Meas" refers to a continuous measurement station performed by a $24-\mathrm{h}$ remote monitoring sound level meter, while the points labeled "MP" indicate point-based measurements.

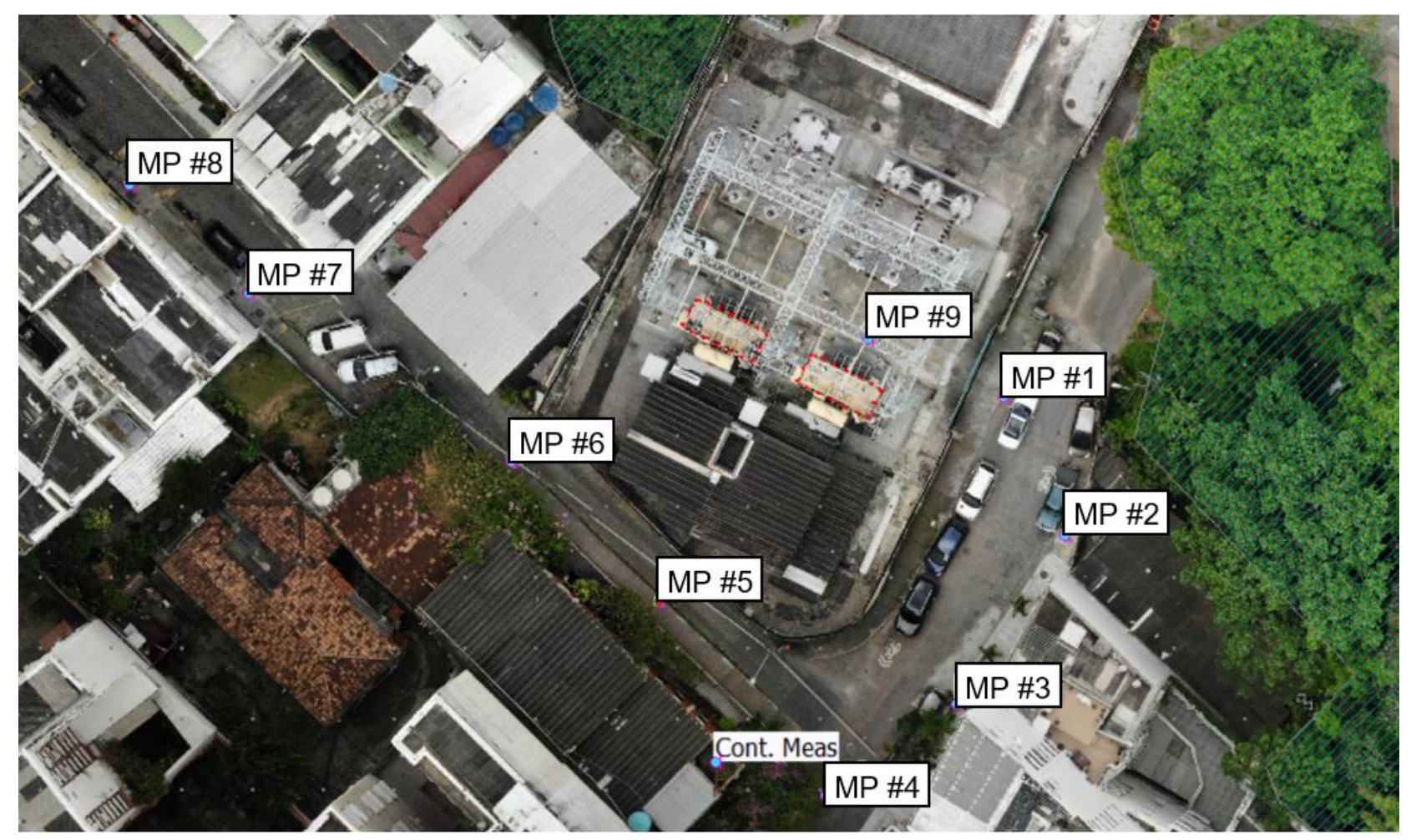

Figure 3. Sound pressure measurement locations in the vicinity of the substation.

The sound pressure level was assessed by a calibrated CESVA SC420 Type 1 sound level meter (expanded uncertainty of $0.9 \mathrm{~dB}$, for a Coverage Factor $k=2$, as stated in the Calibration Certificate issued by the accredited laboratory that performed the calibration). The sound level meter is equipped with a 1/3 octave band spectral analyzer, capable of performing A-weighting measurements, maintaining the microphone positioned $1.5 \mathrm{~m}$ above the ground level, for each one of the measurement points, while the continuous 24-h measurements were performed by a surveillance acoustic sensor CESVA TA120. The effect of wind speed was not considered, given the protection imposed by the presence of buildings throughout the neighborhood.

In the internal environment of the substation, measurements were carried out in front of the transformers, positioning the microphone $2 \mathrm{~m}$ away from it and $1.5 \mathrm{~m}$ from the ground, in the point labeled as "MP \#9" in Figure 3. Figure 4 shows the spectrum associated with the mapping of the primary sources of noise. This is actually a screenshot of the software Adobe Audition, used in sound studios for recording, mixing, and mastering musical instruments. Thus, this is not software specifically designed for noise analysis, and as such it does not follow the standardized frequency spectrum bands. Thus, the tonal frequencies identified for the frequencies $125 \mathrm{~Hz}, 345 \mathrm{~Hz}$, and $609 \mathrm{~Hz}$, associated with the band centers defined by default by the Adobe Audition software, are the closest to the actual frequencies resulting from the magnetostriction phenomenon that generates the hum of the transformer at $120 \mathrm{~Hz}, 240 \mathrm{~Hz}$, and $360 \mathrm{~Hz}$, which are harmonics of the excitation current at $60 \mathrm{~Hz}$. 


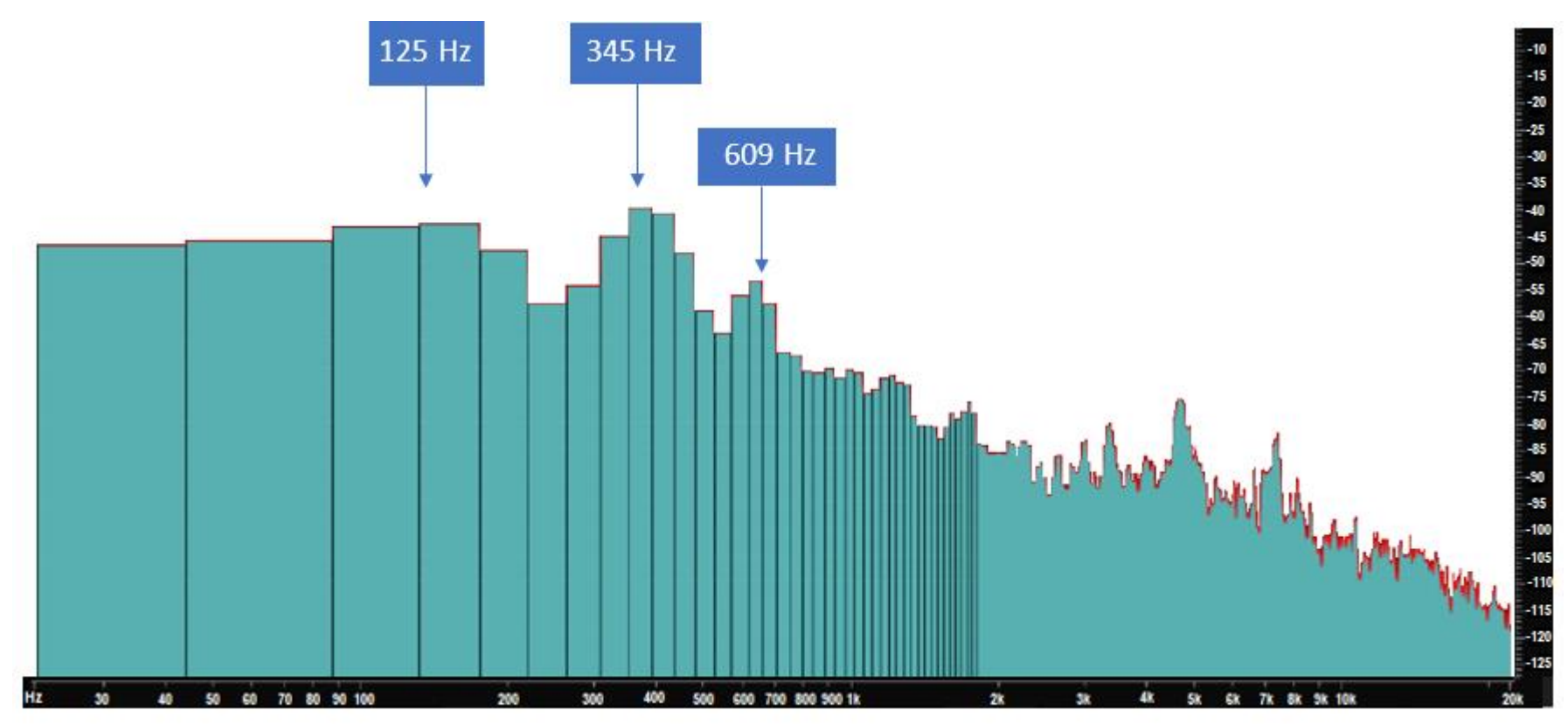

Figure 4. Frequency spectrum measured $2 \mathrm{~m}$ in front of the transformer, at the point labeled "MP \#9" in Figure 3.

The measurement campaign identified $L A_{\text {eq,sp }}$ levels above the applicable limit defined by the applicable environmental legislation, which defines $55 \mathrm{~dB}$ and $50 \mathrm{~dB}$ for the daytime and nighttime periods, respectively. Since there are tonal frequencies present in the spectrum, the legislation applies a penalty of $+5 \mathrm{~dB}$ over the measured values, which makes the effort to ensure compliance with the acceptable standard limits even more challenging for the electricity utility responsible for the operation of the substation.

\subsection{Synthetizing of the Masking Samples}

The main role of the acoustic masking system is to flatten the frequency spectrum around the identified tonal frequencies, thereby avoiding the $+5 \mathrm{~dB}$ penalty applied by environmental legislation, and reducing the discomfort perceived by the human ear, thus enhancing the soundscape. The masking process was implemented through an electronic synthesis simulating natural sounds of nature, with frequencies in the side bands between the ranges $100 \mathrm{~Hz}$ to $160 \mathrm{~Hz}, 250 \mathrm{~Hz}$ to $400 \mathrm{~Hz}$, and $560 \mathrm{~Hz}$ to $700 \mathrm{~Hz}$, aiming to mask the tonal noises identified at $125 \mathrm{~Hz}, 345 \mathrm{~Hz}$, and $609 \mathrm{~Hz}$, respectively.

The sounds to be superimposed to the sound generated by the power transformers were selected based on the study of their acoustic properties and literature research [10-12], which describe a significant improvement of the soundscape through the external inclusion of such masking sounds. Among the nature sounds selected, the songs of three nocturnal birds present in the Brazilian Atlantic region were investigated and incorporated into the masking sound: (i) the yellow-bellied Murucutu (Pulsatrix koeniswaldiana) or Tawnybrowed Owl [13]; (ii) the Urutau (Nyctibius griséus) Grey Potoo [14]; and (iii) the JuruvaBaryphthengus ruficapillus (Rufous-capped Motmot) [15].

A MIDI controller/synthesizer (Roli Seaboard Rise 49), with EQUATOR software and Adobe audition CC 12.0 software, was used to perform a sound synthesis and postproduction process.

From the first acoustic tests that aimed to superimpose a masking sound on the acoustic noise generated by the operation of the transformers, it was possible to synthesize different alternatives of sound arrangements using sounds induced by noise associated with the movement of a river and waterfalls, the noise of rain, insects humming, and bird songs from the Atlantic Forest (Essay \# 1). Using different process racks from Adobe Audition, it was possible to adjust the spectrum to the critical frequencies of interest. Once the sample to be used was obtained, it was mixed with the noise sample of the transformers, 
as illustrated in Figure 5, clearly showing a decrease in amplitude between the side bands of the tonal frequencies of $125 \mathrm{~Hz}, 345 \mathrm{~Hz}$, and $609 \mathrm{~Hz}$, effectively masking the tonal characteristic of the hum generated by both transformers.

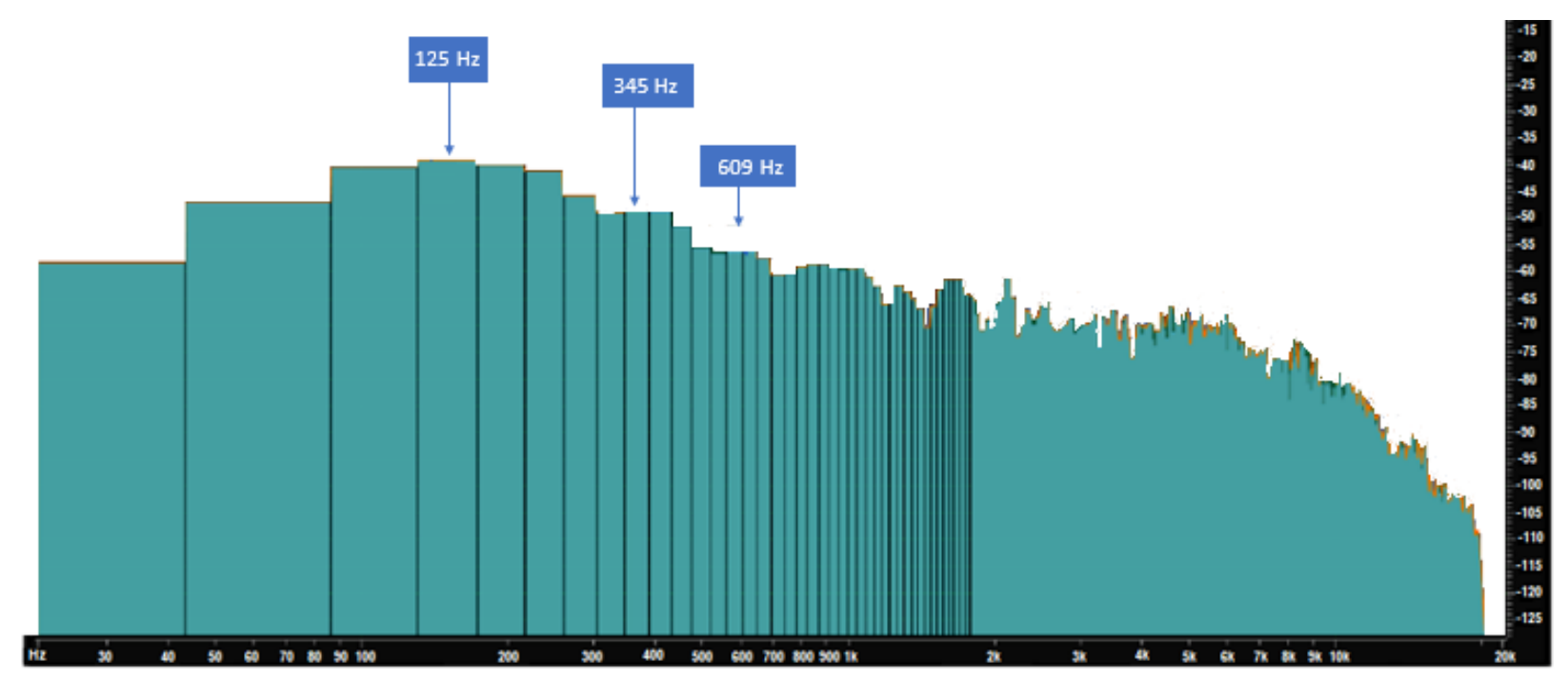

Figure 5. Frequency spectrum of the synthesized sample mixed with the noise generated by the transformers.

These preliminary results validated the premises raised by the study and extracted from the literature, to carry out additional tests to analyze the superposition of the masking sound (including its harmonization) with the environmental sound that emerged from the substation.

\subsection{Design of the Masking System}

The acoustic masking system is conceived with the objective of eliminating the tonal component in the noise generated by high voltage transformers-which causes discomfort to the human ear and penalizes the measured levels by $+5 \mathrm{~dB}$ - understood as the primary source of environmental noise generated in the electrical substation studied.

During the day, the random noise from the surroundings, called "background noise", varies depending on the activities in the community. People who speak, vehicles in transit, workers, animals in nature, etc., produce an acoustic noise level that manages to mask the noise of the transformers; however, at night, this background noise is much lower, and the tonal characteristics of the transformers are exposed. To overcome this difficulty, an external sound synthesized in the laboratory was superimposed on the main acoustic signal generated by the operation of the transformers, assigning to it a stationary random characteristic that converts the annoying sound into a reasonable "pleasant acoustic landscape", reducing drastically the irritation perceived by the human ear. That is, the acoustic masking signal aims to occupy the lateral frequencies of the tonal component generated by the noise of the transformers, without increasing the acoustic level of the general environment. The masking signal feeds an audio amplifier and is inserted into the environment by means of weather-resistant speakers. In other words, by removing the tonal characteristics, the artificially introduced masking system contributes to increasing the human ear's tolerance to irritation caused by acoustic noise and avoids the $+5 \mathrm{~dB}$ penalty imposed by legislation.

The control system of the masking system was developed in Python in a Raspberry Pi embedded computer, running the Debian Linux system, with the following characteristics:

- $\quad$ Python version: Python 3.7.3

- Operating system: "Raspbian GNU/Linux" version 10.4 "buster"

- Kernel version: 5.4.51-v7 + \# 1333

- Hardware version: Raspberry Pi model 3 
The system, depicted in Figure 6, illustrates the subsystems that make up the masking system. Through the program developed in Python, the researchers play the masking sounds, which are amplified by a power mixer. The system can be used directly through a touch-sensitive human-machine interface screen (shown in Figure 7) or remotely through an internal connection. As a protection element against operator or system errors, and in order to improve the measurement and regulation of the sound pressure level in $\mathrm{dB}$ that is being reproduced, an acoustic limiter LRF05 was used, with its sensor microphone positioned in front of the loudspeakers PSB CS100 (150 W, 6-8 ohms). An internet server stores soundtracks and data collected by both the system and the limiter.

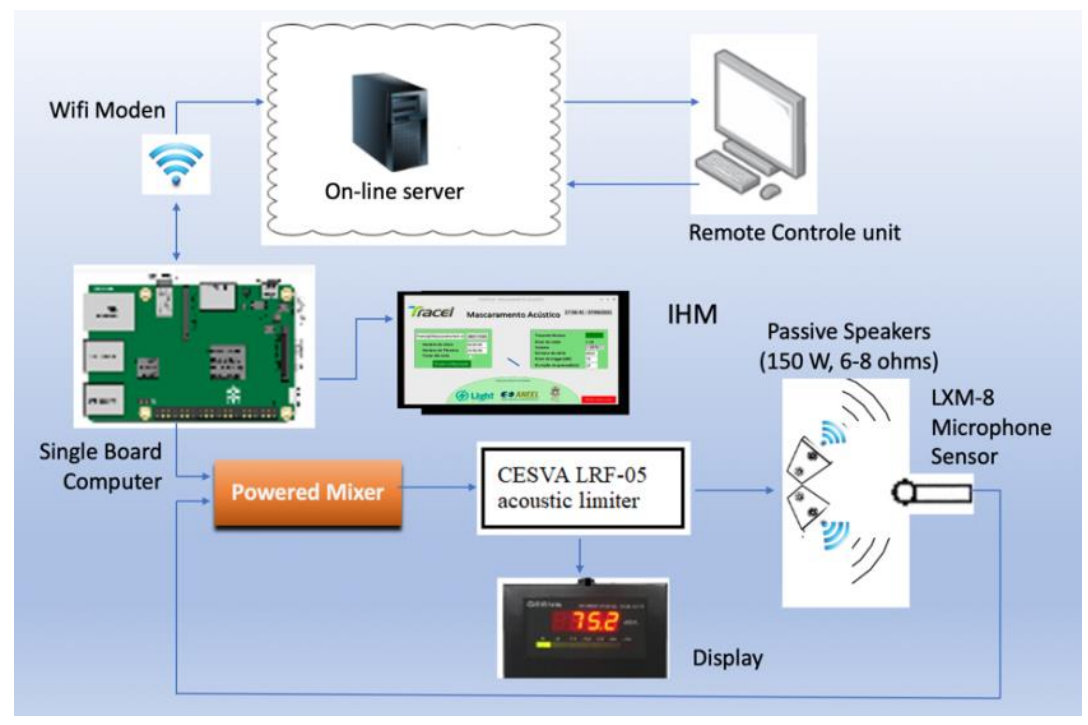

Figure 6. Block diagram of the masking system.

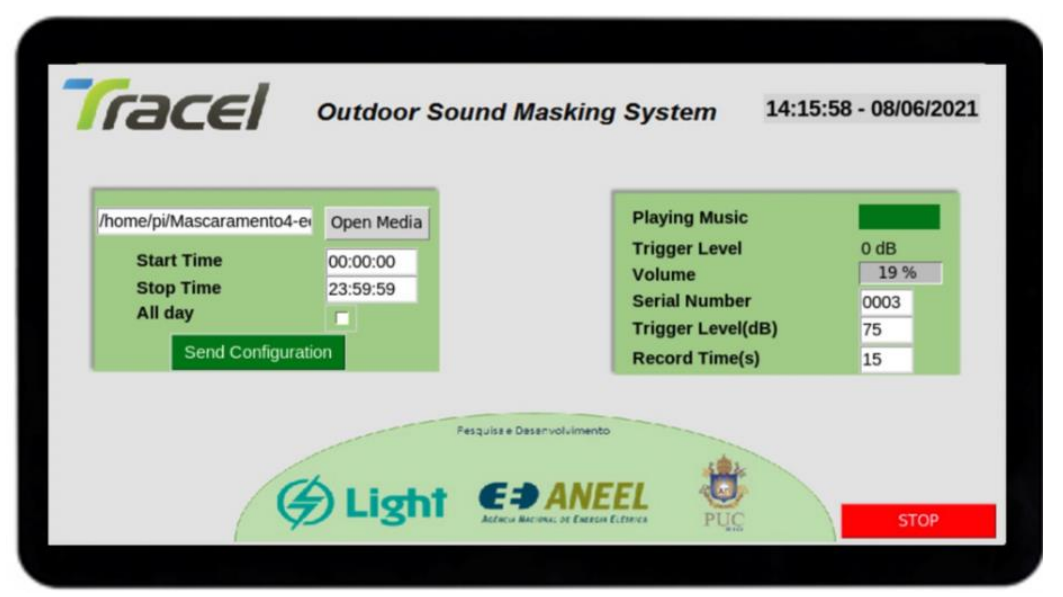

Figure 7. HMI display of the masking system and its operating functions.

The system reproduces a sound of water as a baseline, to attend the lateral bands of the tonal of the transformer, and also allows the random reproduction of synthesized sounds of birds at pre-programmed periods of the day. Conceived to offer a friendly interaction with the system operator, the system incorporates a $7^{\prime \prime}$ HMI (human-machine interface) touch screen interface that allows the interchange of the masking sound type and its execution by pre-programmable periods, whose functions can be selected by the operator, directly on the screen (Figure 8) of the masking system. 

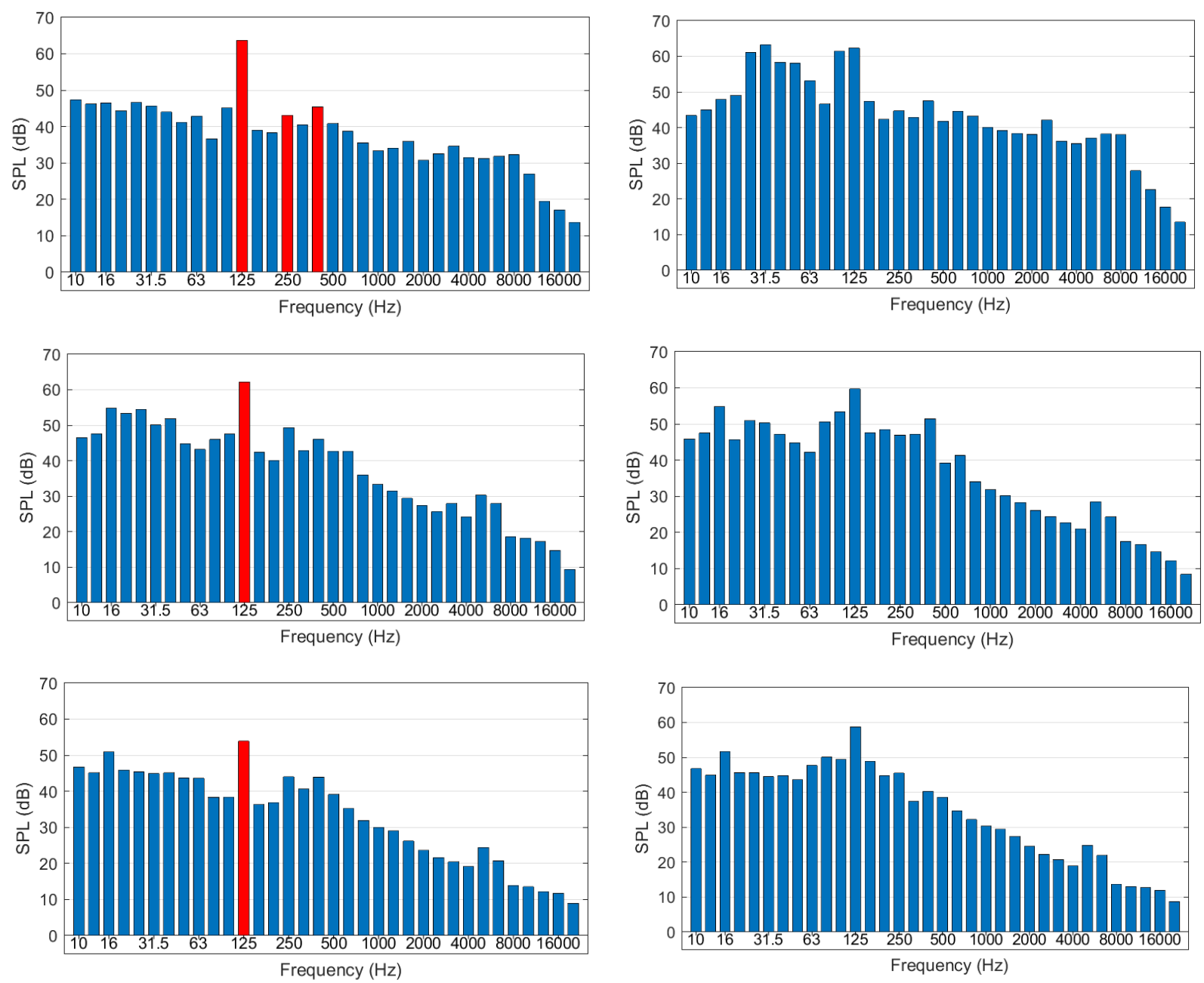

Figure 8. Sound pressure frequency spectra in the absence and presence of sound masking. The images on the left refer to spectra measured with the masking system turned off, while those on the right refer to spectra measured under the effect of the masking system. The three lines correspond to measurement points \#2, \#3, and \#6, respectively.

\section{Results}

After being validated in the laboratory, the performance of the masking system was evaluated in situ, in the neighborhood of the high-voltage substation studied. The amplitude and spectrum of the sound pressure generated by the transformers in operation were monitored externally to the substation with the masking system, installed, and activated within the internal environment of the substation. The reference microphone was installed in positions of measurement points \#2, \#3, and \#6 (shown in Figure 3). All acoustic pressure measurements were performed with the calibrated sound meter CESVA SC 420, for the two acoustic conditions studied, i.e., with the masking system activated and deactivated, thus allowing the comparison of the acoustic noise spectra obtained for both studied situations. To establish compliance, the measurement results were also compared with the limits of the sound pressure level recommended by the Brazilian standard ABNT NBR 10151:2019 [8], as defined in Table 1.

Figure 8 shows the respective processed frequency spectra for the three selected measurement points positioned in the vicinity of the substation. The images on the left document the respective spectra in the absence of the masking effect (disabled masking system) while the images on the right document the respective frequency spectra under the effect of the masking sound superimposed on the sound induced by the operation of substation, i.e., with the masking system activated. 
The frequency spectra shown in the images on the left of Figure 8 clearly indicate the existence of potential tonal components in the acoustic signal (characterized by red bars) for all three sound pressure measurement campaigns carried out at measurement points \#2, \#3, and \#6. This is, however, only a visual finding made explicit by visual inspection of the frequency spectrum graphs. As shown in Table 2, which documents the processed results of the sound pressure measurement level (SPL), it is necessary to be aware of the existence of false positives (failure to meet the criteria defined in Table 1 ) in this process of identifying possible tonal components. This is the case of the results associated with measurement point \#2 which, although presenting three peaks (red bars) at the frequencies of $125 \mathrm{~Hz}, 250 \mathrm{~Hz}$, and $400 \mathrm{~Hz}$, in fact, only one of them (at the frequency of $125 \mathrm{~Hz}$ ) can be characterized as tonal when the regulation criteria are applied. The peaks at frequencies of $250 \mathrm{~Hz}$ and $400 \mathrm{~Hz}$ simply reflect the presence of harmonics and should be disregarded as they do not meet the criteria defined in Table 1.

Table 2. Processing of measurements to identify the tonal component of noise. The red color indicates values that exceed the criteria defined in Table 1.

\begin{tabular}{|c|c|c|c|c|c|c|c|c|}
\hline \multirow{3}{*}{$\begin{array}{l}\text { Measurement } \\
\text { Point \# }\end{array}$} & \multicolumn{2}{|c|}{ Frequency Bands (Hz) } & \multirow{2}{*}{\multicolumn{3}{|c|}{$\begin{array}{l}\text { Measurements with the Masking System Disabled } \\
\qquad L_{e q}(\mathrm{~dB})\end{array}$}} & \multirow{2}{*}{\multicolumn{3}{|c|}{$\begin{array}{l}\text { Measurements with the Masking System Activated } \\
\qquad L_{e q}(\mathrm{~dB})\end{array}$}} \\
\hline & \multirow[b]{2}{*}{$\begin{array}{l}\text { Central } \\
\text { Band (cb) }\end{array}$} & \multirow[b]{2}{*}{$\begin{array}{l}\text { Adjacent } \\
\text { Bands } \\
\text { (ab) }\end{array}$} & & & & & & \\
\hline & & & $\begin{array}{l}\text { Central } \\
\text { Band (cb) }\end{array}$ & $\begin{array}{c}\text { Adjacent } \\
\text { Bands (ab) }\end{array}$ & $\begin{array}{c}\Delta P(\mathrm{~dB}) \\
\text { Arithmetic Difference } \\
\left|L_{e q}(c b)-L_{e q}(a b)\right|\end{array}$ & $\begin{array}{l}\text { Central } \\
\text { Band (cb) }\end{array}$ & $\begin{array}{c}\text { Adjacent } \\
\text { Bands (ab) }\end{array}$ & $\begin{array}{c}\Delta P(\mathrm{~dB}) \\
\text { Arithmetic Difference } \\
\left|L_{e q}(c b)-L_{e q}(a b)\right|\end{array}$ \\
\hline \multirow{3}{*}{ Meas.Point \#2 } & 125 & $\begin{array}{l}100 \\
160\end{array}$ & 63.7 & $\begin{array}{l}45.1 \\
39.0\end{array}$ & $\begin{array}{l}18.6 \\
24.7\end{array}$ & 62.3 & $\begin{array}{l}61.4 \\
47.5\end{array}$ & $\begin{array}{l}0.9 \\
14.8\end{array}$ \\
\hline & 250 & $\begin{array}{l}200 \\
315\end{array}$ & 43.1 & $\begin{array}{l}38.3 \\
40.5\end{array}$ & $\begin{array}{l}4.8 \\
2.6\end{array}$ & 44.7 & $\begin{array}{l}42.3 \\
42.9\end{array}$ & $\begin{array}{l}2.4 \\
1.8\end{array}$ \\
\hline & 400 & $\begin{array}{l}315 \\
500\end{array}$ & 45.4 & $\begin{array}{l}40.5 \\
40.8\end{array}$ & $\begin{array}{l}4.9 \\
4.6\end{array}$ & 47.5 & $\begin{array}{l}42.9 \\
41.8\end{array}$ & $\begin{array}{l}4.6 \\
5.7\end{array}$ \\
\hline \multirow{3}{*}{ Meas.Point \#3 } & 125 & $\begin{array}{l}100 \\
160 \\
\end{array}$ & 62.2 & $\begin{array}{l}47.5 \\
42.4 \\
\end{array}$ & $\begin{array}{l}14.7 \\
19.8 \\
\end{array}$ & 59.7 & $\begin{array}{l}53.4 \\
47.6 \\
\end{array}$ & $\begin{array}{c}6.3 \\
12.1 \\
\end{array}$ \\
\hline & 250 & $\begin{array}{l}200 \\
315\end{array}$ & 49.3 & $\begin{array}{l}40.1 \\
42.9\end{array}$ & $\begin{array}{l}9.2 \\
6.4\end{array}$ & 46.9 & $\begin{array}{l}48.5 \\
47.2\end{array}$ & $\begin{array}{l}1.6 \\
0.3\end{array}$ \\
\hline & 400 & $\begin{array}{l}315 \\
500\end{array}$ & 46.1 & $\begin{array}{l}42.9 \\
42.7\end{array}$ & $\begin{array}{l}3.2 \\
3.4\end{array}$ & 51.4 & $\begin{array}{l}47.2 \\
39.2\end{array}$ & $\begin{array}{c}4.2 \\
12.2\end{array}$ \\
\hline \multirow{3}{*}{ Meas.Point \#6 } & 125 & $\begin{array}{l}100 \\
160\end{array}$ & 53.9 & $\begin{array}{l}38.4 \\
36.3\end{array}$ & $\begin{array}{l}15.5 \\
17.6\end{array}$ & 58.7 & $\begin{array}{l}49.4 \\
48.9\end{array}$ & $\begin{array}{l}9.3 \\
9.8\end{array}$ \\
\hline & 250 & $\begin{array}{l}200 \\
315 \\
\end{array}$ & 44,0 & $\begin{array}{l}36.9 \\
40.6 \\
\end{array}$ & $\begin{array}{l}7.1 \\
3.4 \\
\end{array}$ & 45.5 & $\begin{array}{l}44.8 \\
37.4 \\
\end{array}$ & $\begin{array}{l}0.7 \\
8.1 \\
\end{array}$ \\
\hline & 400 & $\begin{array}{l}315 \\
500\end{array}$ & 43.9 & $\begin{array}{l}40.6 \\
39.1\end{array}$ & $\begin{array}{l}3.3 \\
4.8\end{array}$ & 40.3 & $\begin{array}{l}37.4 \\
38.6\end{array}$ & $\begin{array}{l}2.9 \\
1.7\end{array}$ \\
\hline
\end{tabular}

As shown by the arithmetic differences between the values of the acoustic pressure measured in the central band and in the respective adjacent bands, for all three measurement points $(\# 2, \# 3$, and \#6), the results shown in red confirm the presence of tonal for the $125 \mathrm{~Hz}$ frequency, that is, $\Delta P(\mathrm{~dB}) \geq 15 \mathrm{~dB}$. It is important to note here that the criterion needs to be met for both adjacent frequencies.

Just to elucidate this framing criterion, it is worth noticing that for the results of measuring point \#3, at the frequency of $250 \mathrm{~Hz}$, the regulation criteria of Table 1 is only satisfied for one of the adjacent frequencies. For this case, the applicable filter criterion considered in Table 2 is $\Delta P(\mathrm{~dB}) \geq 8 \mathrm{~dB}$. As shown in the left part of Table 2, which summarizes the data associated with measurements when the masking system remained disabled, for the data associated with measurement point \#3, at the frequency of $250 \mathrm{~Hz}$, the module of the arithmetic difference of the results of measurements performed in the central band and in the respective adjacent bands only meets the criterion for the value $9.2 \mathrm{~dB}(49.3 \mathrm{~dB}-40.1 \mathrm{~dB})$, which is not true for the value $6.4 \mathrm{~dB}(49.3 \mathrm{~dB}-42.9 \mathrm{~dB})$, thus not confirming the tonal hypothesis.

The superposition of masking sounds, as a strategy to eliminate the tonal characteristics of acoustic noise, proved to be effective at the substation studied. In addition to the benefits caused by masking, it should be noted that the superposition of the masking signal to the acoustic field generated by the operation of the substation does not always increase 
the intensity of the acoustic pressure associated with the combined acoustic field. This fact is exemplified by the comparison of the results of the measurement of acoustic pressure at the frequency of $125 \mathrm{~Hz}$, carried out at measurement points \#2 and \#3, in which the value of the acoustic pressure decreased by $1.4 \mathrm{~dB}$ (from $63.7 \mathrm{~dB}$ to $62.3 \mathrm{~dB}$ at measurement point \#2) and has fallen by $2.5 \mathrm{~dB}$ (from $62.2 \mathrm{~dB}$ to $59.7 \mathrm{~dB}$ at measurement point \#3). In contrast, the masking effect increased $4.8 \mathrm{~dB}$ (from $53.9 \mathrm{~dB}$ to $58.7 \mathrm{~dB}$ at measurement point \#6 furthest from the substation) at the same $125 \mathrm{~Hz}$ frequency.

Contrary to what should be expected when the masking signal is superimposed on other acoustic noises in an open field, the reduction in the intensity of the sound pressure at points \#2 and \#3 can be explained by an adverse action of masking on standing waves that can be formed in confined environments, as occurred at measurement points \#2 and \#3, closest to the access gate of the substation. The presence of standing waves was detected by a 3D Camera operated by 48 microphones arranged in a ring shape, whose technique and applications are discussed elsewhere [16].

In order to assess the stability of the noise generated by the transformers and by the masking system, Figure 9 presents spectrograms of the sound pressure level at measurement point \#6.
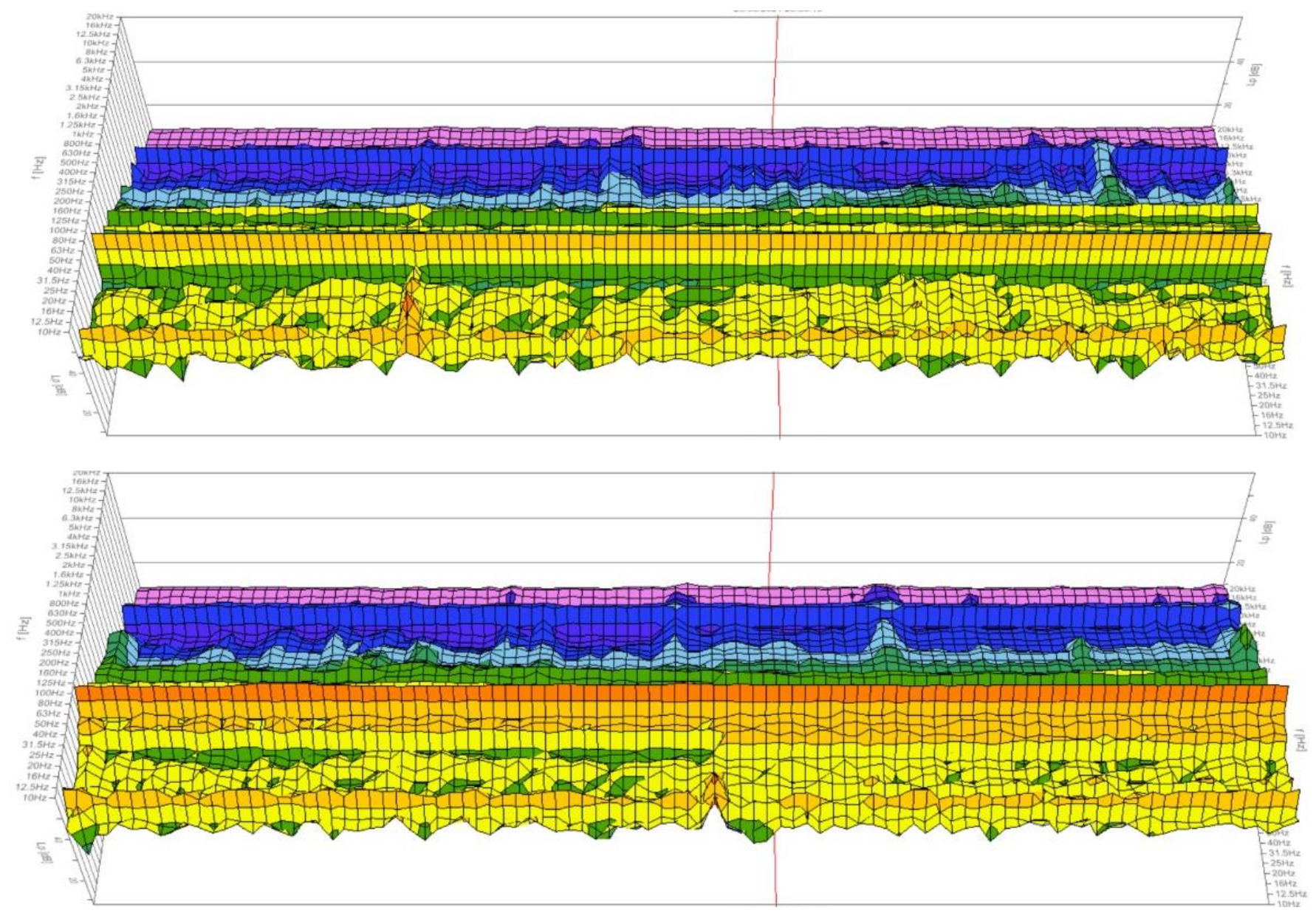

Figure 9. Spectrograms of the sound pressure levels measured at measurement point \#6, in the absence and presence of sound masking. The top image refers to spectra measured with the masking system turned off, while the bottom image refers to spectra measured under the effect of the masking system.

Finally, Figure 10 presents the sound pressure levels $L_{A e q, 1 s}$ at measurement point \#6, in the absence and presence of sound masking. 

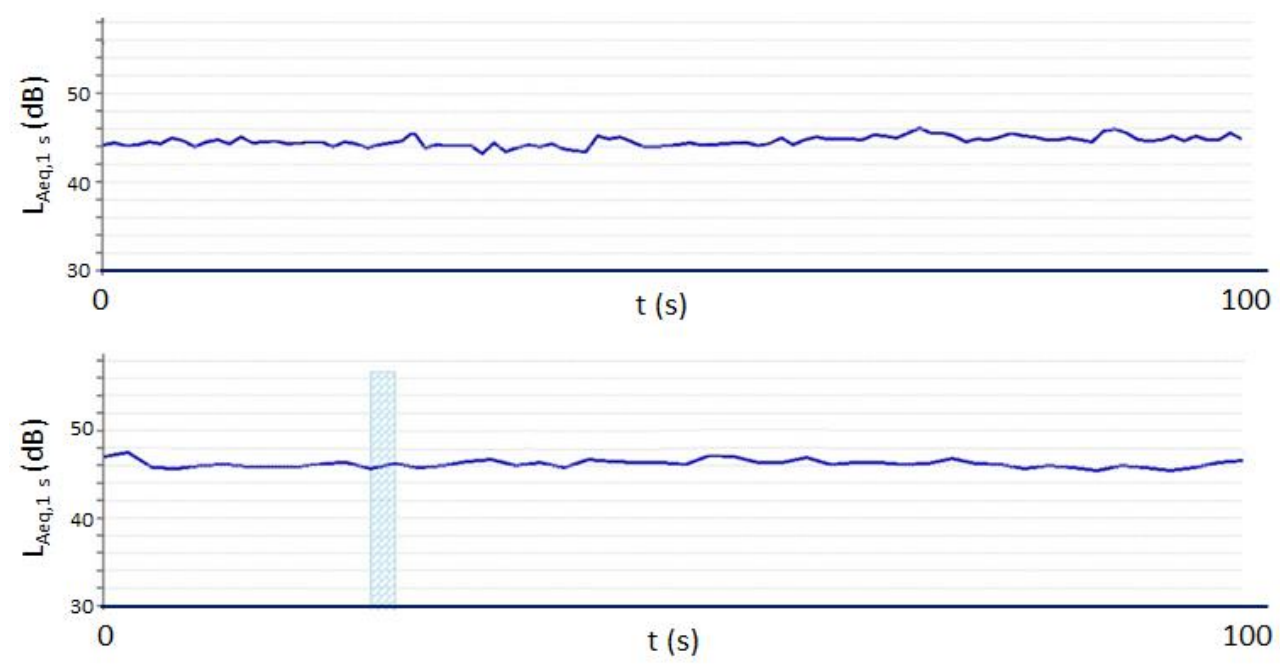

Figure 10. Sound pressure levels measured at measurement point \#6, in the absence and presence of sound masking. The top image refers to the levels measured with the masking system turned off, while the bottom image refers to the levels measured under the effect of the masking system. The blue shaded area indicates a region that has been edited to remove the sound of a dog barking.

Once the tonal component of the acoustic noise was identified based on the regulation criteria defined in Table 1 -which incurs a penalty of $+5 \mathrm{~dB}$ in the measured values-measurements were taken of the occupational and environmental noise descriptors, characterized by mean values to over a period of time $\left(T_{e}=5 \mathrm{~min}\right)$, expressed by instantaneous values that result from the weighting based on Curve A, expressed by Equation (2).

To represent the physical characteristics of the measurement of a quantity that varies in the fields of frequency and time, the CESVA SC 420 sound meter also performs independent measurements of the acoustic descriptors $L_{10}$ and $L_{95}$ previously described.

Data in Table 3 summarizes measurement results of the characteristic statistical descriptors performed at the same three measurement points \#2, \#3, and \#6, at 11:30 p.m.; i.e., near the changeover from day to night periods (the night period starts at 10:00 p.m. and ends at 10:00 a.m.). In this table, $L A_{e q}$ denotes the value corresponding to the value $L_{e q}$ shown in Table 2, but weighted in Curve A. The value $L_{R}$ is defined by the value of $L_{95}$, penalized by $+5 \mathrm{~dB}$ in cases where the tonal component in noise is present, as explained in Section 2.3.

Table 3. Results of measurements of characteristic statistical descriptors. The red color indicates values that exceed the legal limit for the night period $(50 \mathrm{~dB})$.

\begin{tabular}{|c|c|c|c|c|c|c|c|c|}
\hline \multirow{3}{*}{ Measuring Point \# } & \multicolumn{4}{|c|}{ Measurements with the Masking System Disabled } & \multicolumn{4}{|c|}{ Measurements with the Masking System Activated } \\
\hline & $L A_{\mathrm{eq}}$ & $L_{10}$ & $L_{95}$ & $L_{R}$ & $L A_{\mathrm{eq}}$ & $L_{10}$ & $L_{95}$ & $L_{R}$ \\
\hline & $(\mathrm{dB})$ & (dB) & (dB) & $(\mathrm{dB})$ & $(\mathrm{dB})$ & (dB) & (dB) & $(\mathrm{dB})$ \\
\hline Meas.Point \#2 & 50.3 & 50.2 & 50.2 & 55.2 & 53.1 & 55.7 & 50.9 & 50.9 \\
\hline Meas.Point \#3 & 49.9 & 50.4 & 48.8 & 53.8 & 50.4 & 51.1 & 48.8 & 48.8 \\
\hline Meas.Point \#6 & 44.7 & 45.5 & 43.3 & 48.3 & 46.3 & 46.8 & 45.7 & 45.7 \\
\hline
\end{tabular}

The results shown in Table 3 confirm, for all three measurement points investigated, that, when properly implemented, the masking sound (continuous noise) is able to flatten the tonal characteristics associated with the background noise (i.e., compliance of the descriptor $L_{R}$ with the regulation). Except for the value $50.9 \mathrm{~dB}$ (measured at measurement point \#2), all other values comply with the regulation imposed for the night period $(<50 \mathrm{~dB})$. This small discrepancy in the threshold value should not be a matter of concern as this measurement point is very close to the heavy steel access gate of the substation, whose 
proximity distorts the measurement (acoustic wave reverberation), as shown in Figure 3, which is far from the location inhabited by a potential claimant.

The results also show that the masking sound practically does not increase the amplitude of the combined acoustic signal (i.e., the value of $L_{95}$ is not considerably affected by the masking sound introduced).

\section{Conclusions}

This article presented a new approach to mitigating noise pollution acting on the acoustic landscape of external environments, masking emissions that bother or are unpleasant for the population. Based on tests supported by a structured program for monitoring and measuring the sound pressure in the presence and absence of the action of the sound masking system, it proved to be effective in eliminating the tonal noise of the target noise, which results from the operation of the electric substation. When eliminating the tonal characteristics, one benefits from the applicable technical standard (NBR 10151:2019) that imposes a penalty of $+5 \mathrm{~dB}$ on the measured values of the sound pressure level. This assumption is supported by the fact that the equivalent sound pressure levels did not exceed the $15 \mathrm{~dB}$ difference limit for the $125 \mathrm{~Hz}$ adjacent bands and $8 \mathrm{~dB}$ for the $400 \mathrm{~Hz}$ adjacent bands, no longer incurring in the $+5 \mathrm{~dB}$ penalty imposed by the NBR 10151:2019 standard [8].

From a legal point of view, the efficacy of the sound masking system was also proven by the fact that the public civil action filed by the residents of the substation's neighborhood was canceled based on an independent assessment carried out in the substation environment at the initiative of the Public Ministry.

Author Contributions: Conceptualization, R.R., B.C. and H.V.d.M.; data curation, B.C. and J.J.G.A.; formal analysis, R.R., B.C., H.V.d.M., J.J.G.A., C.R.H.B. and M.N.F.; funding acquisition, M.N.F.; investigation, R.R., B.C., H.V.d.M., J.J.G.A., C.R.H.B. and M.N.F.; methodology, R.R., B.C., H.V.d.M., J.J.G.A., C.R.H.B. and M.N.F.; project administration, M.N.F., J.V.S. and C.A.M.G.; resources, R.R., H.V.d.M., M.N.F., J.V.S. and C.A.M.G.; software, B.C. and H.V.d.M.; supervision, C.R.H.B. and M.N.F.; validation, R.R., B.C. and H.V.d.M.; visualization, B.C. and J.J.G.A.; writing-original draft, J.J.G.A., C.R.H.B. and M.N.F.; writing-review and editing, C.R.H.B. and M.N.F. All authors have read and agreed to the published version of the manuscript.

Funding: This work was financed by the regulated R\&D program coordinated by the regulatory body of the Brazilian electrical system (Anneal), through Project R\&D Light-Aneel 00382-0128/2019.

Institutional Review Board Statement: Not applicable.

Informed Consent Statement: Not applicable.

Data Availability Statement: The data presented in this study are available on request from the corresponding author. The data are not publicly available due to privacy.

Acknowledgments: Thanks are due to Light Energia S/A and the National Electric Energy Agency (Aneel) for financing the R\&D project Light/Aneel 00382-0128/2019, in the context of which this work was developed. This study was financed in part by the Coordenação de Aperfeiçoamento de Pessoal de Nível Superior-Brasil (CAPES)—Finance Code 001.

Conflicts of Interest: The authors declare no conflict of interest. The funders had no role in the design of the study; in the collection, analyses, or interpretation of data; in the writing of the manuscript, or in the decision to publish the results.

\section{References}

1. Berglund, B.; Hassmén, P. Sources and effects of low-frequency noise. J. Acoust. Soc. Am. 1996, 99, 2985. [CrossRef] [PubMed]

2. Seixas, N.S.; Neitzel, R.; Stover, B.; Sheppard, L.; Feeney, P.; Mills, D.; Kujawa, S. 10-Year prospective study of noise exposure and hearing damage among construction workers. Occup. Environ. Med. 2012, 69, 643-650. [CrossRef] [PubMed]

3. Piana, E.A.; Roozen, N.B. On the Control of Low-Frequency Audible Noise from Electrical Substations: A Case Study. Appl. Sci. 2020, 10, 637. [CrossRef]

4. Ying, L.; Wang, D.; Wang, J.; Wang, G.; Wu, X.; Liu, J. Power Transformer Spatial Acoustic Radiation Characteristics Analysis under Multiple Operating Conditions. Energies 2018, 11, 74. [CrossRef] 
5. Keerthipala, W.W.L.; Jing, Z.R.; Leong, T.E.; Jinn, C.C. Electronic Circuits for Active Control of Acoustic Noise Generated by High Voltage Transformers. In Proceedings of the 1998 International Conference on Power Electronic Drives and Energy Systems for Industrial Growth, Perth, WA, Australia, 1-3 December 1998; Volume 1, pp. 243-248.

6. ISO 1996-1:2016. Acoustics_Description Measurement and Assessment of Environmental Noise_Part 1: Basic Quantities, Assessment Procedures, 3rd ed.; ISO: Geneva, Switzerland, 2016.

7. ISO 1996-2:2017. Acoustics—Description Measurement and Assessment of Environmental Noise_Part 2: Determination of Sound Pressure Levels; ISO: Geneva, Switzerland, 2017.

8. NBR 10151:2019 Standard. Acústica-Medição e Avaliação de Níveis de Pressão Sonora em Áreas Habitadas—Aplicação de Uso Geral; ABNT: Rio de Janeiro, Brazil, 2019.

9. Charles, J.G. The Effect of the Level of Magnetostriction upon Noise E Vibration of Model Single-Phase Transformer; Electrical Research Association (ERA): Leatherhead, UK, 1967.

10. Watts, G.R.; Pheasant, R.J.; Horoshenkov, K.V.; Ragonesi, L. Measurement and subjective assessment of water generated sounds. Acta Acust. United Acust. 2009, 95, 1032-1039. [CrossRef]

11. Coensel, B.D.; Vanwetswinkel, S.; Botteldooren, D. Effects of Natural Sounds on the Perception of Road Traffic Noise. J. Acoust. Soc. Am. 2011, 129, EL148-EL153. [CrossRef] [PubMed]

12. Jeon, J.Y.; Lee, P.J.; You, J.; Kang, J. Acoustical characteristics of water sounds for soundscape enhancement in urban open spaces. J. Acoust. Soc. Am. 2012, 131, 2101-2109. [CrossRef] [PubMed]

13. Menq, W.; Anjos, L. Habitat selection by owls in a seasonal semi-deciduous forest in southern Brazil. Braz. J. Biol. 2015, 75, 143-149. [CrossRef] [PubMed]

14. Mendonça, L.G.A.; Blamires, D.; Tubelis, D.P. Nesting of the Common Potoo, Nyctibius griseus (Gmelin, 1789)(Aves: Nyctibiidae) in an urban environment in central Cerrado. Lundiana Int. J. Biodivers. 2009, 10, 77-79.

15. Pagotto, A.H.; Muscat, E.; Stuginski, D.R. Predatory behavior of a rufous-capped motmot (Baryphthengus ruficapillus) on a mammal (Monodelphis sp.). Ornitol. Neotrop. 2019, 30, 229-231.

16. Frota, M.N.; Souza, J.V. Control of Sound Pressure Levels in Energy Substation; R\&D Project Reports, Light/Aneel 00382-0128/2019; Contract \# 4500429234, Signed in Oct/2019; 2019; in press. 